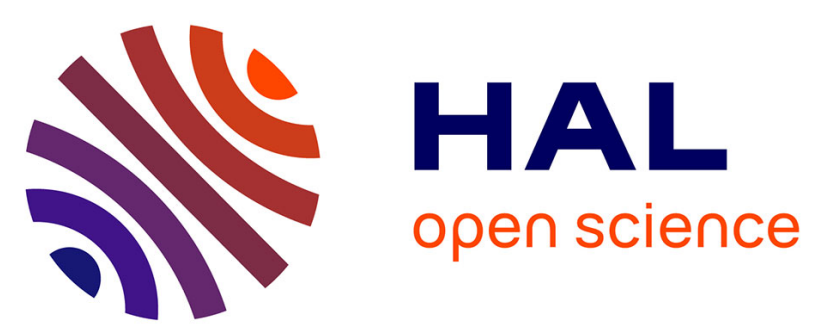

\title{
Multiple-site decontamination regimen without systemic antibiotics associated with reduced mortality in intubated patients
}

Nicolas Massart, Pierre Fillatre, Guilhem Wattecamps, Christophe Camus

\section{- To cite this version:}

Nicolas Massart, Pierre Fillatre, Guilhem Wattecamps, Christophe Camus. Multiple-site decontamination regimen without systemic antibiotics associated with reduced mortality in intubated patients. Infectious diseases (London, England), 2020, 52 (7), pp.513-516. 10.1080/23744235.2020.1754457. hal-02563364

HAL Id: hal-02563364 https://hal-univ-rennes1.archives-ouvertes.fr/hal-02563364

Submitted on 10 Jun 2020

HAL is a multi-disciplinary open access archive for the deposit and dissemination of scientific research documents, whether they are published or not. The documents may come from teaching and research institutions in France or abroad, or from public or private research centers.
L'archive ouverte pluridisciplinaire HAL, est destinée au dépôt et à la diffusion de documents scientifiques de niveau recherche, publiés ou non, émanant des établissements d'enseignement et de recherche français ou étrangers, des laboratoires publics ou privés. 
Multiple-site decontamination regimen without systemic antibiotics associated with reduced mortality in intubated patients

Nicolas MASSART, MD ${ }^{1,2,3}$, Pierre FILLATRE, MD³, Guilhem WATTECAMPS, MD ${ }^{4}$, Christophe CAMUS, MD $\mathrm{PhD}^{1,2,5}$.

${ }^{1}$ Service des Maladies Infectieuses et Réanimation Médicale, Centre Hospitalo-universitaire de Rennes, 2, rue Henri le Guilloux 35033 Rennes, France.

${ }^{2}$ Université Rennes1, Faculté de Médecine, Biosit, F-35043 Rennes, France

${ }^{3}$ Service de Réanimation, CH de St BRIEUC, 10, rue Henri le Guilloux 22000 Saint-Brieuc, France.

${ }^{4}$ Service de Réanimation, CH de QUIMPER, 14bis Avenue Yves Thépot, 29107 Quimper.

${ }^{5}$ Inserm-CIC-1414, Faculté de Médecine, Université Rennes I, IFR 140, F-35033 Rennes,

France

Corresponding Author : Nicolas MASSART, Service des Maladies Infectieuses et Réanimation Médicale, 2, rue Henri le Guilloux 35033 Rennes, France. Telephone +33 620 1759 89, Email: nicolasmassart@ hotmail.fr

Author Contributions: All authors contributed to the acquisition of data. PF, CC and NM conducted the statistical analysis, $\mathrm{CC}$ and $\mathrm{NM}$ contributed to the study conception and design as well as the analysis and interpretation of the data. CC and NM drafted the manuscript, and all authors critically revised the manuscript and approved the final version. 
Declaration of Interest: None

Availability of data and material: The data are available from the corresponding author for reasonable demand.

Running Title: Multiple-site decontamination in ICU patients. 
To the Editor

The results of a study on Pseudomonas aeruginosa ventilator-associated pneumonia, reported in this journal, suggested that initial combination therapy followed by early deescalation had no impact on mortality, raising concerns about the appropriate management of pneumonia in the intensive care unit (ICU) [1]. Perspectives are different in ICUs with low multidrug-resistance prevalence rate, because antimicrobial therapy issues are simpler and infection prevention is more prominent. Selective digestive decontamination with systemic antibiotics has been shown to decrease ICU-acquired pneumonia and bloodstream infection and to reduce mortality in patients most often receiving mechanical ventilation. We performed a post-hoc analysis of an observational retrospective study in three ICUs with low multidrug-resistance prevalence rate. Mortality was compared for patients receiving standard care versus patients receiving a selective digestive combined with nasal and cutaneous decontamination regimen.

The study was conducted in three French ICUs with an average extended-spectrum beta-lactamase-producing Gram-negative bacilli prevalence rate of 6\% [2]. ICU 1 was a medical ICU with 22 acute-care beds in a tertiary university hospital and ICUs 2 and 3 were polyvalent ICUs with 14 and 12 acute-care beds, respectively. In addition to standard care, ICU 1 used a multiple-site decontamination regimen for the prevention of acquired infections in intubated patients. Multiple-site decontamination is a variant of selective digestive decontamination and consists of the administration of topical antibiotics (tobramycin, polymyxin and amphotericin B) four times daily in the oropharynx and the gastric tube without systemic antibiotics, chlorhexidine body washing twice a day and a 5-day nasal mupirocin course in all intubated patients who had an expected intubation duration of 24 hours or more, throughout the duration of intubation. Full details about the multiple-site decontamination regimen have been reported elsewhere [3]. Patients in ICUs 2 and 3 received 
standard care alone. Patients who required intubation for an expected duration greater than two day were eligible for study and divided into two groups: multiple-site decontamination group (ICU 1) and standard care group (ICUs 2 and 3).

Each center had a nosocomial infection committee for the prevention and prospective census of acquired infections and applied the recommendations of the French Society for Hospital Hygiene for the prevention and treatment of infection (available at https://sf2h.net/publications/actualisation-precautions-standard-2017). Because report of acquired infections is a routine care, the institutional ethics committee approved the study and written informed consent was waived. Infection was considered ICU-acquired when it was diagnosed 48 hours after admission or later and not incubating on admission. The diagnosis of pneumonia was made on clinical signs (fever) radiological findings (new infiltrate on chestX-ray or CT scan), and a positive microbiological culture of an endotracheal aspirate $\left(\geq 10^{6}\right.$ colony-forming units $/ \mathrm{mL})$ or a broncho-alveolar lavage ( $\geq 10^{4}$ colony-forming units $\left./ \mathrm{mL}\right)$ as recommended by the Centers for Disease Control and Prevention [4]. Bloodstream infection was diagnosed with at least one positive blood culture for a significant pathogen and two positives blood cultures drawn on separate occasions for common skin contaminants as defined by the CDC [4]. The primary endpoint was ICU mortality and secondary endpoints were the incidence of pneumonia and bloodstream infection.

Statistical analysis was performed with R 3.4.3. Qualitative variables were expressed as numbers (percent) and quantitative variables as medians (interquartile range [IQR]). The chisquare test and the Fisher's exact test were used to compare categorical variables and the Man-Whitney U test was used for continuous variables. Kaplan-Meier ICU survival curves were compared with the log-rank test. Multivariate analysis was made using logistic regression and the Cox proportional-hazards regression model when appropriate. The following covariates including age, sex, reason for admission (medical/surgical) and 
simplified acute physiology score II (SAPS II) at admission were included in the model, as performed in other studies [5]. All tests were two-sided, and a p-value $\leq 0.05$ was considered statistically significant.

Among 3,861 admissions from January 2016 to September 2017, 1,368 patients were intubated longer than 2 days and were included in the study, respectively 676 and 680 in the multiple-site decontamination and standard care groups. Compared to the standard care group, patients in the multiple-site decontamination group were younger (62 [51-70] years versus 64 [53-74] years, $\mathrm{p}=0.005)$, had higher SAPS II score at admission (52 [38-65]) versus 50 [3563 ] respectively, $\mathrm{p}=0.013)$, were less likely to be admitted for surgery (10\% versus $17 \%$, $\mathrm{p}<0.001)$ and had a longer length of stay in ICU (10 [3-17] days versus 8 [3-15] days, $\mathrm{p}=0.002)($ Table 1).

The probability of remaining alive with time in ICU was higher in the multiple-site decontamination group (Figure 1, $\mathrm{p}=0.01$ ). Compared to standard care, the adjusted hazard ratio for death in ICU at day-28 in the multiple-site decontamination group versus the standard care group was 0.75 (95\% confidence interval $0.64-0.90, \mathrm{p}=0.01)$. Crude mortality in ICU was $27.2 \%$ in the multiple-site decontamination group and $31.0 \%$ in the standard care group (adjusted OR 0.69 [0.52-0.90], p=0.007; Table 1). Compared to standard care, fewer patients acquired pneumonia ( $4.1 \%$ versus $12.6 \%, \mathrm{p}=0.001)$, bloodstream infection $(3.4 \%$ versus $6.7 \%, \mathrm{p}=0.006)$ and overall infections caused by Pseudomonas aeruginosa $(1.0 \%$ vs $3.5 \%, \mathrm{p}=0.004)$ in the multiple-site decontamination group. Time to first acquired infection was similar in the multiple-site decontamination and the standard care groups (10 [6-25] days and $12[5-26]$ days, $\mathrm{p}=0.97)$.

In this study conducted in ICUs with low-level antimicrobial resistance, the use of a selective digestive decontamination regimen was associated with a lower ICU mortality rate and lower acquisition rates of pneumonia and bloodstream infection than the use of standard 
care alone. The relatively high rate of bloodstream infection in the standard care group, higher than usually reported by the Réa-Raisin surveillance network (available at http://www.cpiasile-de-france.fr/surveillance/rea/2017/Rapport_REA2017.pdf), could be related to the $100 \%$ rate of intubation in our study population compared to only $59 \%$ to $67 \%$ in the Réa-Raisin database, depending on the year studied. Indeed, intubation $>48$ hours has been shown to increase the risk of acquired infection [3]. In our study, the incidence of pneumonia (combining ventilator-associated and other healthcare-associated pneumonia) compared favorably to the $12.5 \%$ mean rate reported by the French network for ventilator-associated pneumonia alone.

The favorable effect of infection prevention by selective digestive decontamination or selective oral decontamination regimens on mortality in ICU is controversial. In a large metaanalysis including 36 randomized controlled trials, total mortality was reduced in trials comparing a combination of topical and systemic antibiotics to controls, but not with topical antibiotics alone [6]. Selective oral decontamination has been shown to reduce mortality by 2.9 percentage points compared to standard care in the Netherlands [5]. However, compared to selective oral decontamination, selective digestive decontamination was associated to lower mortality. In contrast, in European ICUs with intermediate or high level antimicrobial resistance, a selective digestive decontamination regimen without systemic antibiotics did not decreased mortality compared to other interventions (chlorhexidine mouthwash, selective oral decontamination) or standard care [7].

In France, a multicenter controlled trial of selective digestive decontamination without systemic antibiotics performed in 1990 had not shown improved survival compared to placebos [8]. In contrast, our study, which shows for the first time a benefit on mortality with a selective digestive decontamination regimen in France, highlights the rationale of the recent French recommendations for the prevention of acquired pneumonia in ICUs with a prevalence 
rate of multidrug resistant bacteria below 20\% [9]. In a randomized controlled trial performed according to a $2 \times 2$ factorial design, Camus et al. reported for the first time that the combination of selective digestive decontamination using topical antibiotics alone with chlorhexidine body washing and nasal mupirocin decreased all-cause acquired infections compared to placebos [10]. Interestingly, although the study was not powered to assess mortality, ICU mortality tended to be lower with all-drugs regimen than with placebos $(21.7 \%$ versus $32.5 \%, \mathrm{p}=0.052$ ) while the length of stay in ICU was similar in both groups [10].

The main limitations of the present study were the retrospective observational design, the existence of differences between groups at baseline and the possible reduced sensitivity of microbiological culture of respiratory samples for the diagnosis of pneumonia with multiplesite decontamination. However, patients in the multiple-site decontamination group were at higher risk for infection because they were more severe as evidenced by a higher severity score despite younger age and had a longer length of stay in ICU.

In conclusion, the association of oropharyngeal and digestive topical antibiotics (tobramycin, polymyxin and amphotericin B) with nasal mupirocin and chlorhexidine body wash was associated with lower ICU mortality in intubated patients hospitalized in ICUs with low multidrug resistance prevalence rate.

\section{Acknowledgements :}

The authors thanks all the people involved in the collection of the data: Clarisse DUPIN, Florence LE GALL, Caroline PIAU, François BENEZIT, Mikaël MORICONI

\section{Competiting interest :}


The Authors have no conflict of interest to declare.

\section{Ethic approval :}

This observational retrospective study respects the MR003 convention. Patients were informed of the study and non-opposition was needed. By the French law, there was no need for patient's written approval. The local ethic committee approved the protocol $\left(\mathrm{n}^{\circ} 18.52\right)$.

\section{References :}

[1] Deconinck L, Meybeck A, Patoz P, et al. Impact of combination threrapy and earlyi deescalation on outcome of ventilator-associated pneumonia caused by Pseudomonas aeruginosa. Infect Dis (London) 2017;49:396-404.

[2] - Massart, N., Camus, C., Benezit, F. et al. Incidence and risk factors for acquired colonization and infection due to extended-spectrum beta-lactamase-producing Gramnegative bacilli: a retrospective analysis in three ICUs with low multidrug resistance rate. Eur J Clin Microbiol Infect Dis (2020) doi:10.1007/s10096-019-03800-y

[3] - Camus C, Salomon S, Bouchigny C, Gacouin A, Lavoué S, Donnio P-Y, et al. ShortTerm Decline in All-Cause Acquired Infections With the Routine Use of a Decontamination Regimen Combining Topical Polymyxin, Tobramycin, and Amphotericin B With Mupirocin and Chlorhexidine in the ICU: A Single-Center Experience. Crit Care Med 2014; 42(5):112130. 
[4] - Pneumonia (Ventilator-associated [VAP] and non-ventilator-associated Pneumonia [PNEU]) Event; available at https://www.cdc.gov/nhsn/PDFs/pscManual/6pscVAPcurrent.pdf ;Bloodstream Infection Event (Central Line-Associated Bloodstream Infection and Noncentral Line Associated Bloodstream Infection); available at https://www.cdc.gov/nhsn/PDFs/pscManual/4PSC_CLABScurrent.pdf.

[5] - de Smet AM, Kluytmans JA, Cooper BS, Mascini EM, Benus RF, van der Werf TS, et al. Decontamination of the digestive tract and oropharynx in ICU patients. N Engl J Med 2009;360:20-31.

[6] - Liberati A, D’Amico R, Pifferi S, Torri V, Brazzi L, Parmelli E. Antibiotic prophylaxis to reduce respiratory tract infections and mortality in adults receiving intensive care. Cochrane Database Syst Rev 2009:CD000022.

[7] - Wittekamp BH, Plantinga NL, Cooper BS, et al. Decontamination strategies and bloodstream infections with antibiotic-resistant microorganisms in ventilated patients: a randomized clinical trial. JAMA 2018;320(20):2087-2098.

[8] - Gastinne H, Wolff M, Delatour F et al. A controlled trial in intensive care units of selective decontamination of the digestive tract with non-absorbable antibiotics. N Engl $\mathbf{J}$ Med 1992; 326:594-599. 
[9] - Leone M, Bouadma L, Bouhemad B, Brissaud O, Dauger S, Gibot S, et al. Brief summary of French guidelines for the prevention, diagnosis and treatment of hospitalacquired pneumonia in ICU. Ann Intensive Care 2018 3;8(1):104.

[10] - Camus C, Bellissant E, Sebille V, Perrotin D, Garo B, Legras A, et al. Prevention of acquired infections in intubated patients with the combination of two decontamination regimens. Crit Care Med 2005;33(2):307-314. 
Table 1. Characteristics and outcomes of study patients.

\begin{tabular}{|c|c|c|c|c|c|c|}
\hline Variables & $\begin{array}{c}\text { Multiple-site } \\
\text { decontamination } \\
(n=676)\end{array}$ & $\begin{array}{c}\text { Standard } \\
\text { care } \\
(\mathrm{n}=680)\end{array}$ & $\begin{array}{c}\mathrm{OR} \\
{[95 \% \mathrm{CI}]}\end{array}$ & p-value & $\begin{array}{c}\text { Adjusted OR } \\
{[95 \% \mathrm{CI}]}\end{array}$ & p-value \\
\hline Age, year (IQR) & $62(51-70)$ & $64(53-74)$ & & & & \\
\hline Simplified Acute Physiology Score II (IQR) & $52(38-65)$ & $50(35-63)$ & & & & \\
\hline Male - no. (\%) & $439(64.9)$ & $470(69.1)$ & & & & \\
\hline \multicolumn{7}{|l|}{ Reason for admission } \\
\hline Surgical - no. (\%) & $64(9.5)$ & $118(17.4)$ & & & & \\
\hline Medical-no. $(\%)$ & $612(90.5)$ & $387(56.9)$ & & & & \\
\hline Not specified - no. $(\%)$ & 0 & $175(25.7)$ & & & & \\
\hline Length of stay in ICU, days (IQR) & $10(3-17)$ & $8(3-15)$ & & & & \\
\hline Survivors, days (IQR) & 11(3-17) & $8[3-16]$ & & & & \\
\hline Dead, days (IQR) & $7(3-14)$ & $7(3-14)$ & & & & \\
\hline Death in ICU - no. (\%) & $184(27.2)$ & $211(31.0)$ & $0.83[0.66-1.05]$ & 0.12 & $0.69[0.52-0.90]$ & 0.007 \\
\hline \multicolumn{7}{|l|}{ Infections acquired in ICU } \\
\hline Pneumonia - no. $(\%)$ & $28(4.1)$ & $86(12.6)$ & $0.30[0.19-0.47]$ & $<0.001$ & $0.28[0.18-0.46]$ & $<0.001$ \\
\hline Bloodstream infection - no. (\%) & $23(3.4)$ & $46(6.7)$ & $0.48[0.29-0.81]$ & 0.006 & $0.41[0.24-0.71]$ & 0.001 \\
\hline $\begin{array}{l}\text { Infections caused by Pseudomonas } \\
\text { aeruginosa-no. (\%) }\end{array}$ & $7(1.0)$ & $24(3.5)$ & $0.29[0.12-0.69]$ & 0.004 & $0.26[0.11-0.63]$ & 0.003 \\
\hline
\end{tabular}




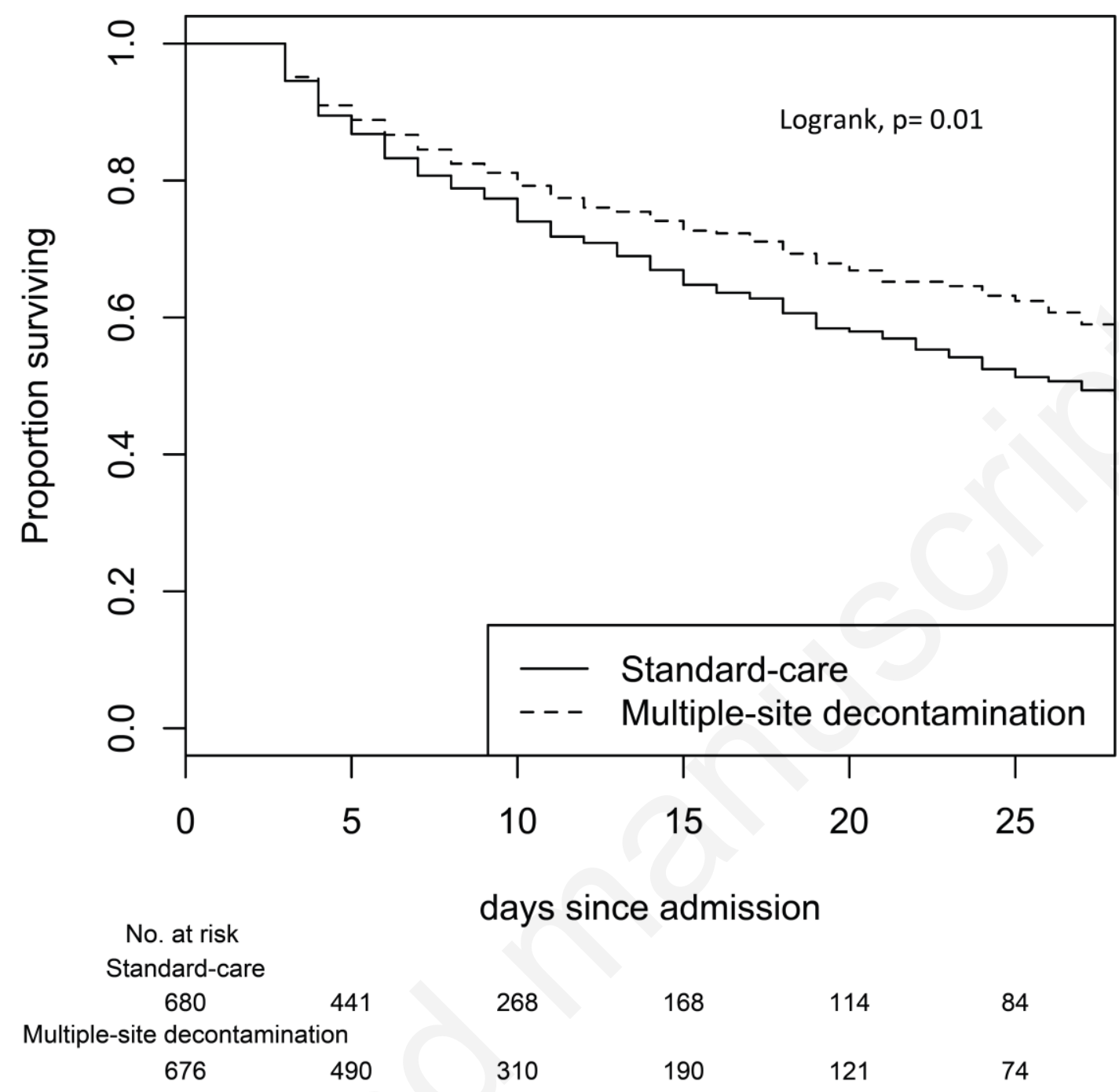

Figure 1. ICU survival of study patients. 